\title{
Utilização do Antibiograma Como Ferramenta de Tipagem Fenotípica de Escherichia coli Isolada de Linguiça Frescal
}

\author{
Samira Obeid Georges (I), Larissa Gomes Bernardo (I), Maria \\ Cláudia Dantas Porfírio Borges André (II), Liana Jayme Borges (I) \\ (I) FANUT/ UFG - Faculdade de Nutrição da Universidade Federal de Goiás (Rua 227 Qd.68 \\ S/N-Setor Leste Universitário-Goiânia(GO)-Brasil-CEP:74.605-080), (II) IPTSP/ UFG - Instituto \\ de Patologia Tropical e Saúde (Rua 235 S/N esquina com a 1ª Avenida-Setor Leste \\ Universitário-Goiânia(GO))
}

\section{Resumo}

Introdução. Quadros de toxinfecções alimentares estão cada vez mais frequentes. Grande quantidade desses quadros está relacionada ao aumento do consumo de produtos frescais, como a linguiça, sendo que a Escherichia coli foi o quarto agente etiológico mais envolvido em surtos nos anos de 2000 a abril de 2013. A necessidade de monitorar a resistência a antimicrobianos tem sido presente, visto que em situações de graves toxinfecções, a administração de medicamentos se torna fundamental. Material e Métodos. Foram coletadas em açougues do Município de Aparecida de Goiânia - Goiás, 87 amostras de linguiça frescal nos meses de julho a agosto de 2013. Posteriormente, as amostras foram submetidas à análise microbiológica de acordo com a RDC $n^{\circ} 12 / 2001$. De todas as amostras, foram isoladas sete E. coli, sendo duas de uma mesma linguiça. Todas elas foram submetidas ao teste do antibiograma, com utilização de nove antibióticos de acordo com o Manual Clinical and Laboratory Standards Institute: Sulfametoxazol Trimetropim (SUT), Ciprofloxacina (CIP), Ceftazidima (CAZ), Aztreonama (ATM), Amoxicilina/ Ácido Clavulâmico (AMC), Imipenema (IPM), Ampicilina (AMP), Gentamicina (GEN) e Tetraciclina (TET). Resultados e Discussão. Das sete amostras, $100 \%$ foram sensíveis à CIP, CAZ, ATM e IPM; para a GEN apenas uma bactéria apresentou resistência, enquanto que para o SUT, duas

\footnotetext{
Referência:

Samira Obeid Georges, Larissa Gomes Bernardo, Maria Cláudia Dantas Porfírio Borges André, Liana Jayme Borges. Utilização do Antibiograma Como Ferramenta de Tipagem Fenotípica de Escherichia Coli Isolada de Linguiça Frescal. In: Anais do $12^{\circ}$ Congresso Latinoamericano de Microbiologia e Higiene de Alimentos - MICROAL 2014 [= Blucher Food Science Proceedings, num.1, vol.1]. São Paulo: Editora Blucher, 2014. 
apresentaram essa característica. Já o antibiótico AMC apresentou duas cepas resistentes e duas em situação de sensibilidade intermediária, enquanto que a AMP e TET incluíram cinco cepas resistentes. Por fim, das sete cepas, cinco foram resistentes a pelo menos um antibiótico (71\%). Foram obtidos, ao final, cinco grupos fenotípicos: A (SSSSSSS); B (SRSSSRS); C (IRSISRR); D (RRSRSRR) e E (SSSSSRS). Destaca-se que das duas amostras representantes da mesma linguiça, observou-se características diferentes para mesmos antibióticos. Resultados como esse refletem a importância de traçar o perfil fenotípico de cada cepa, pois o processo de mutação, ao modificar características dos micro-organismos com rapidez, torna-os importantes fatores de risco para a população. Conclusão. $\mathrm{O}$ antibiograma é um valioso método de triagem em laboratório clínico pela facilidade de uso e interpretação além de ser tecnicamente simples e de baixo custo, sendo eficiente e esclarecedor quando aplicado às cepas de E. coli.

Palavras-Chave: Antimicrobiano, Escherichia coli, Linguiça frescal Agência de Fomento: 